\title{
Cyber Collaboratory-based Sustainable Design Education: A Pedagogical Framework
}

\author{
Kyoung-Yun Kim \\ Department of Industrial \\ and Systems Engineering \\ Wayne State University \\ Detroit, MI, USA \\ $+1-313-577-4396$ \\ kykim@eng.wayne.edu
}

\author{
Karl R. Haapala \\ School of Mechanical, \\ Industrial, and \\ Manufacturing Engineering \\ Oregon State University \\ Corvallis, OR, USA \\ $+1-541-737-3122$ \\ haapalak@engr.orst.edu
}

\author{
Gül E. Okudan \\ Kremer \\ School of Engineering \\ Design \& Department of \\ Industrial and \\ Manufacturing Engineering \\ The Pennsylvania State \\ University \\ University Park, PA, USA \\ +1-814-863-1530 \\ gek3@engr.psu.edu
}

\author{
Michael K. Barbour \\ College of Education \\ Wayne State University \\ Detroit, MI, USA \\ +1-313-577-1693 \\ mkbarbour@gmail.com
}

\begin{abstract}
Educators from across the educational spectrum are faced with challenges in delivering curricula that address sustainability issues This article introduces a cyber-based interactive e-learning platform, entitled the Sustainable Product Development Collaboratory, which is focused on addressing this need. This collaboratory aims to educate a wide spectrum of learners in the concepts of sustainable design and manufacturing by demonstrating the effects of product design on supply chain costs and environmental impacts. In this paper, we discuss the overall conceptual framework of this collaboratory along with pedagogical and instructional methodologies related to collaboratory-based sustainable design education. Finally, a sample learning module is presented along with methods for assessment of student learning and experiences with the collaboratory.
\end{abstract}

\section{Keywords}

Sustainable design education; sustainable product development collaboratory; constructivist learning theory; manufacturing analysis

\section{INTRODUCTION}

This paper introduces an NSF CI-TEAM Demonstration Project, entitled A Sustainable Product Development Collaboratory, which aims to develop and test a collaborative e-learning laboratory for sustainable design and manufacturing. This article discusses the collaboratory framework development and a sample learning module from the project.

Due to challenges of existing science and engineering curricula in addressing technical solutions from a holistic perspective that

Permission to make digital or hard copies of all or part of this work for personal or classroom use is granted without fee provided that copies are not made or distributed for profit or commercial advantage and that copies bear this notice and the full citation on the first page. To copy otherwise, or republish, to post on servers or to redistribute to lists, requires prior specific permission and/or a fee. Copyright @JOCSE, a supported publication of the Shodor Education Foundation Inc. considers economic, environmental, and social aspects (e.g., availability of instructional materials with the requisite multidisciplinary focus), engineers within modern manufacturing companies often undertake ad hoc approaches to sustainable product and process development; often without proper tools or training to do so. One other contributing factor challenging the proliferation of sustainable science and engineering in industry is the focus on recruiting new graduates who demonstrate the potential to make an immediate contribution to technical corporate goals based on their experience [12, 24, 25]. Such practices do not necessarily promote a preference for individuals with a broader knowledge set blending two or more disciplines, a need for adequately addressing sustainability goals.

Researchers and practitioners alike recognize that a vast majority of product cost, quality, and overall sustainability is decided during early design. Despite this fact, sustainable design and manufacturing education remains in its infancy, although Allen et al. [1] described the significant, emerging levels of "grassroots" activities for sustainable design and manufacturing. At the same time, an NSF MT21 Study [19] highlighted the need to improve K-12 student interest in STEM (Science, Technology, Engineering, and Mathematics) disciplines, which is in a "State of Emergency." By coupling traditional engineering skills with a broader sustainability perspective, it is posited that the next generation will be more effectively attracted to careers in engineering.

The collaboratory developed as part of this project will provide a much needed cyber-based tool in support of K-12 online learning. In the United States, the first K-12 schools to begin using online learning included a private school and several public school districts in California, in the early 1990s [4]. This adoption was followed by the introduction of statewide and intra-state virtual schools in Utah, Florida, and New England in the middle of the 1990s [3, 11]. Watson et al. [28] reported that online learning activity is surging in all 50 states and the District of Columbia today. During the 2000-01 school year, Clark [10] estimated that there were between 40,000 and 50,000 K-12 students enrolled in one or more distance education courses. Estimates for the 2010-11 school year placed K-12 online learning enrollment at around 
4,000,000 students [2]. In 2006, Michigan became the first state to require that all students complete some form of online learning in order to graduate from high school (other states, such as New Mexico, Alabama, Florida, and Idaho, as well as a number of individual school districts elsewhere, have followed Michigan's lead). Some experts have even predicted the majority of K-12 education will be delivered using some kind of online learning by the year 2020 [9].

Despite these recent advances however, Barbour and Reeves [5] wrote, "[T]here has been a deficit of rigorous reviews of the literature related to virtual schools" (p. 402). Similarly, Cavanaugh et al. [7] found only a small percentage of the open access literature was based upon systematic research, while most of the literature was based on the experiences or opinions of K-12 online learning practitioners. Further, Rice [23] indicated that “...a paucity of research exists when examining high school students enrolled in virtual schools, and the research base is smaller still when the population of students is further narrowed to the elementary grades" (p. 430). Simply put, while the practice of K-12 online learning is growing at an exponential rate, the availability of empirical research to guide that growth has been lacking. As a response to this need, the collaboratory described herein will also be used as a platform to collect data focusing on how it can enhance learning. The following sections describe the development of the Sustainable Product Development Collaboratory and its use as a pedagogical tool, including the description of a teaching module focused on product design and manufacturing and supply chain analysis, and methods for student assessment.

\section{PROJECT OVERVIEW}

The overarching objective of the CI-TEAM Demonstration Project discussed herein is to convey sustainability principles in the context of product architectural design, manufacturing, assembly, and supply chain decisions to a wide spectrum of active learners, ranging from K-12 students, to university students, and to practitioners. The project will actively engage learners in the development of, and research conducted within the collaboratory. The collaboratory is enabled by user-friendly, license-free webbased tools (e.g., Google SketchUp) to deliver a holistic and broadly usable cyber-platform. The specific goals of this CITEAM project include:

- Deploying a Sustainable Product Development Collaboratory that includes modules to support conceptual design variant generation, life cycle cost and environmental analysis, and supply chain optimization;

- Developing and disseminating educational materials that can provide project-based activities in support of interaction with the Sustainable Product Development Collaboratory;

- Assessing the educational effects, or more specifically, the cyberinfrastructure competency gained through interaction with the Sustainable Product Development Collaboratory, including assessment of activities at the participating universities and user adoption of the cyber-platform; and

- Engaging underrepresented groups and high-school students to promote a diverse workforce that is ready to exploit cyberinfrastructure tools.

Below, we first explain the underlying educational philosophy adopted during the development of the collaboratory and then we present a sample learning module and methods of assessment. Finally, we discuss conclusions and observations based on the collaboratory and learning module development efforts.

\section{PEDAGOGICAL AND INSTRUCTIONAL METHODOLOGIES FOR COLLABORATORY-BASED SUSTAINABLE DESIGN EDUCATION}

Although we had a clear vision that a cyber-based tool and interactive e-learning platform had to be built as introduced above, we opted to think critically and learn from prior literature about what pedagogical and instructional methodologies we should follow to make it more effective. Below, we provide a summary of our findings along with our philosophical direction.

Carew and Mitchell [6] studied engineering academics' conceptions of sustainability and stated that variation in conceptions of sustainability and explicit contestation of the variation in the engineering classroom offers opportunities to enrich undergraduate learning and teaching. In their study, Carew and Mitchell [6] concluded that sustainability education requires a diversity of teaching and learning methods that can consider the role of values and assumptions in sustainable decision-making. One of the ways in which instructional design can be varied is in the autonomy the learner may have in completing learning activities. Prior literature points to the potential positive effect of increasing autonomy as the learners develop intellectually.

Vygotsky [26] observed that learning for children and adolescents is a social process that focuses upon interaction within a zone of proximal development. The zone of proximal development "... is the distance between the actual developmental level as determined by independent problem solving and the level of potential development as determined through problem solving under adult guidance or in collaboration with more capable peers" (Vygotsky [27], p. 86). Cavanaugh et al. [8] suggested, "[S]ince adults have progressed through these stages of cognitive development, delivery of web based education at the adult level need not concentrate on methods that help the learner develop these cognitive skills" (p. 7). Methods designed to help younger learners develop cognitive skills are intended as guidance to ensure that these learners remain in the zone of proximal development. Further, Moore [18] noted that K-12 educators typically are expected to maintain control of the content and method of delivery within the classroom. In fact, Moore even posited that K-12 students "should not be compelled to assume a degree of autonomy they are not ready to handle, and so it is customary in child education for the preparatory and evaluation processes to rest entirely in the hands of the teacher" (p. 84). Simply put, children are not ready to assume high degrees of autonomy, and thus child and adolescent learners require more structure in their educational settings.

The approach employed for scaffolding of learning is an important concern when autonomy of learning is not left to the learner. One compelling approach for scaffolding is constructionism. As a form of constructivist learning theory, constructionism is essentially the process of learning through constructing, or designing or making a product. This learning theory is based on Papert's [20] work with students using the Logo programming language, where they programmed an electronic "turtle" to move about on the screen or a physical "turtle" to move about the floor and leave a marking of 
where the object had traveled. Papert believed that through a process of trial and error, the students learned how to command and debug the "turtle" to create specific geometric shapes (and thus learned mathematical problem-solving and geometry). Papert illustrated how computer programming could be used to help teach these mathematical concepts to students who traditionally struggled with the subject. Recently, constructionism has been adopted by researchers who are interested in what students can learn through the process of designing games [14, 15, 17, 21, 22].

The constructionist line of inquiry has regularly been found to enable students to attain a deeper understanding of the concept being taught, have richer discussions about that content, and retain the knowledge longer than students taught in more traditional, instructor-centric environments. Given these findings, we have been developing the Sustainable Product Development Collaboratory to provide a medium for learning sustainability concepts relevant to product development, manufacturing and supply chain design through constructed knowledge across carefully crafted learning modules.

\section{CONCEPTUAL LEARNING MODULES FOR THE COLLABORATORY}

Learning modules have been developed to demonstrate the effects of different product designs on supply chain costs and environmental impacts by using the Sustainable Product Development Collaboratory, which is comprised of several web application technologies. The collaboratory framework consists of three main modules, i.e., design module, manufacturing analysis module, and supply chain analysis module, as shown in Figure 1. The design platform, which uses Google SketchUp, a freely available 3D modeling tool, communicates with a web-based design/analysis interface, called the "collaboratory portal."

Alternatively, learners can access previously modeled products in the Product Design Database (PDDB) for further cost and environmental analysis. In consideration of the educational context for learners, in particular for K-12 students, a simple and easily accessible design platform is needed, so that learners do not require additional training in model generation and design modification. Accordingly, Google SketchUp was selected as the design platform for the collaboratory.

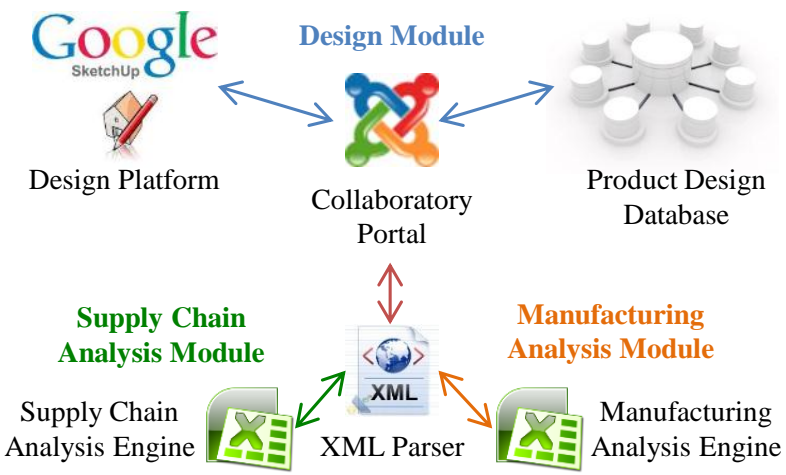

Figure 1. Collaboratory framework showing the portal and design, manufacturing, and supply chain analysis modules.

With limited geometric and engineering analysis functionality, SketchUp represents a 3D modeling tool for beginners. A plugin was developed for the collaboratory to provide basic functions to extract geometric and engineering information. Figure 2 displays the SketchUp plugin for volume calculation developed under this project. If several models or geometries are in the SketchUp platform, the volume calculator will process only the active model, i.e., the component or assembly in the bounding box.

A geometry slicing method is used to determine the solid volume within the bounding box. The selection of accuracy level depends on the complexity (irregularity) of the geometric shape. If the bounding box is assumed to be in stock material dimensions, for instance, subtracting the actual part volume from the bounding box volume determines how much material will be removed during manufacturing. Using basic functions in SketchUp, learners can modify an existing product model or generate a new product model according to their own desire. In addition, the collaboratory library supports the learners with preprocessed component and assembly models. Currently, the library contains the components and assembly of a bicycle pedal.

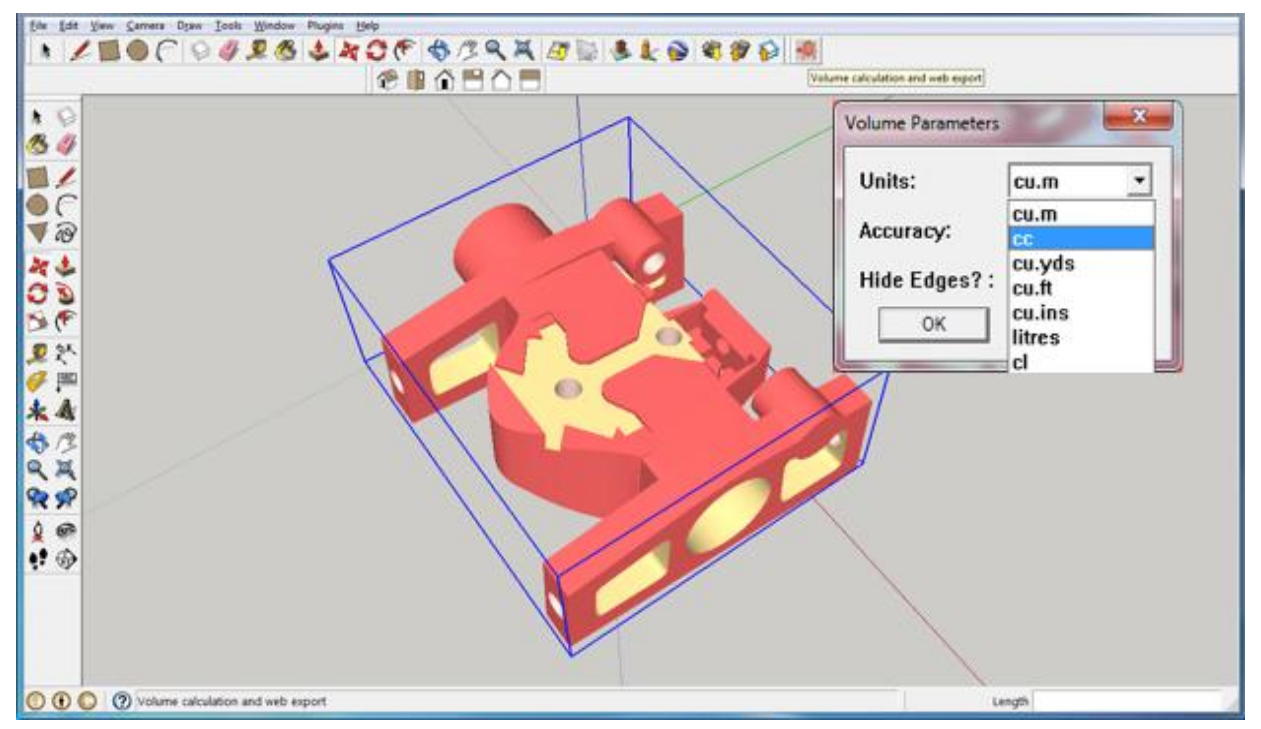

Figure 2. Design platform plug-in for geometry and bounding box volume calculation. 


\section{Sustainable Product Development Collaboratory \\ Portal and System Interface}



Figure 3. Welcome page of the analysis interface.

In addition to product design capabilities, the collaboratory portal provides an interface for the manufacturing analysis module and the supply chain analysis module. The prototype welcome page of the analysis interface is shown in Figure 3. The analysis interface includes the pre-processed model analysis interfaces, a PDDB communication interface, an XML parsing interface, a systemsolver communication interface, and a post-processing interface. The pre-processed model analysis interface provides the user an opportunity to view and select the pre-processed models from the collaboratory library (PDDB). Both assembly level and component level models are available in the library. Learners can browse the assemblies and components, and the design-analysis system interface displays an image of the selected component (Figure 4). Learners can use this interface to download the SketchUp-compatible drawing file from the collaboratory library for further processing and design modification. The file can be modified using SketchUp and exported to the collaboratory library for manufacturing and/or supply chain analysis.

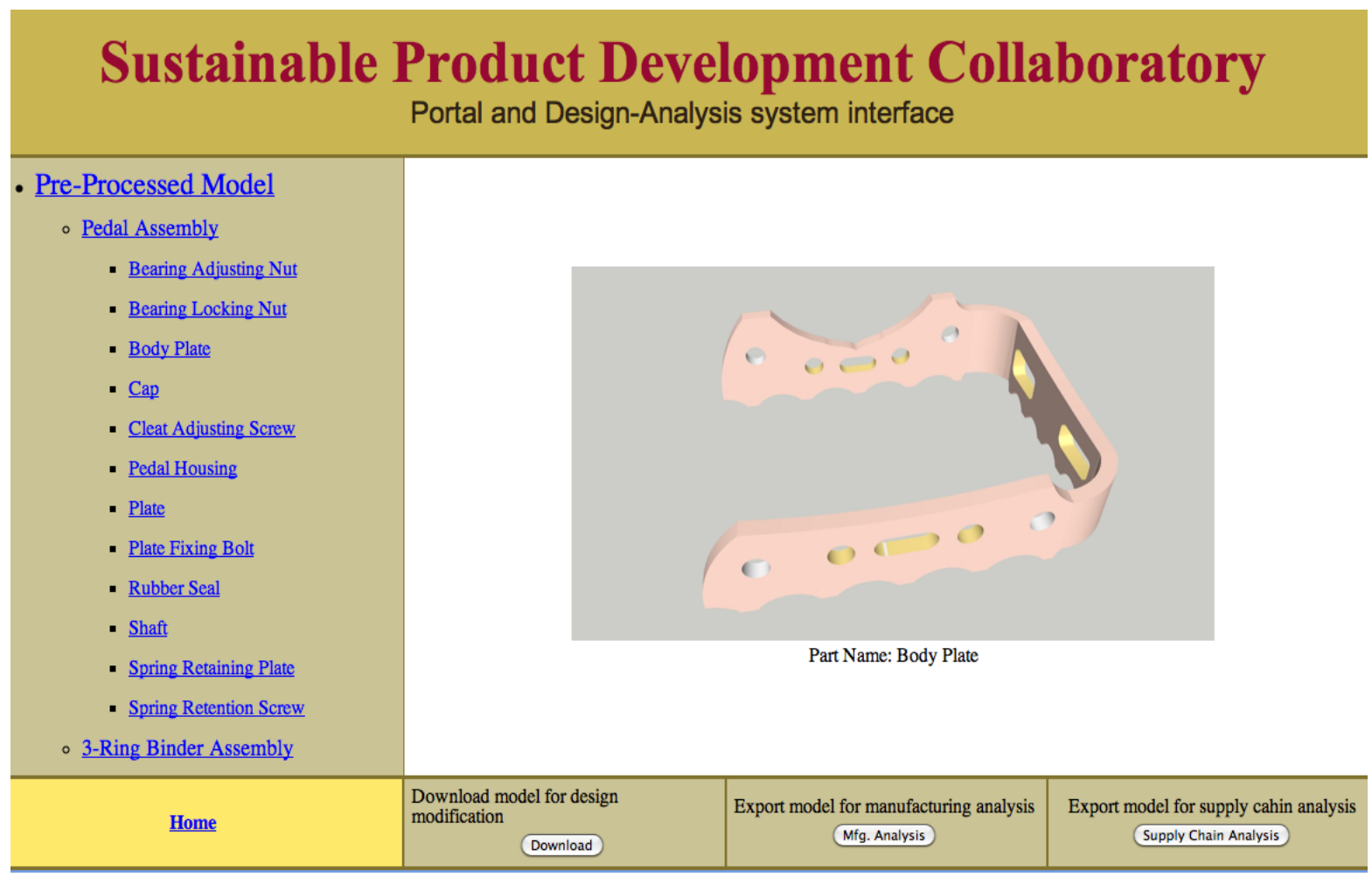

Figure 4. Design-analysis interface showing the body plate component model. 
The design-analysis interface works for both the pre-processed models and newly designed models. For pre-processed models, design, manufacturing, and other analysis data are stored in the PDDB. The PDDB has been designed using MySQL, and the communication between the web portal and the MySQL has been developed using Java. In the case of pre-processed models, the Java code receives the properties from the PDDB corresponding to the selected pre-processed model ID. On the other hand, for a newly designed model, the design properties are stored in the PDDB as required for manufacturing process modeling. This interface has the intelligence to recognize whether the analysis command was initiated for a newly designed model or a preprocessed model. The interface exhibits the corresponding properties, collected from the PDDB, for the selected model and provides the user a place to define additional input parameters. The portal displays basic geometric information taken from the PDDB along with representative input fields (Figure 5).

Ongoing development is extending the PDDB and the input fields based upon the requirements of the manufacturing and supply chain analysis modules. The interface sends all the parameters displayed in the portal to the analysis engines through XML parsers. The manufacturing and supply chain analysis solvers are stored on a central server along with the collaboratory portal. The solver has separate worksheets for input parameters and output parameters. For performing analysis, the analysis interface reads the Excel workbook template stored in the PDDB and creates a copy of the workbook in the PDDB. The purpose of copying the workbook is to keep the workbook template protected from malicious activities.

After creating the new workbook, the interface reads all the input fields and adds the input parameters to the corresponding input fields. If an Excel worksheet contains any formulas, logic, and/or links; the updates made in the input fields are not executed automatically. Execution of the formulas and logic steps is forced by reading all the worksheets. The execution time varies depending on the size and the contents of the workbook. After completing analysis, the interface reads the output worksheet and the output fields. The output parameters are sent to the XML parsing interface for storage and transmission to the postprocessing portal.

Figure 6 illustrates the flow of the manufacturing analysis solver for a set of processes that might be used to fabricate a bicycle pedal body (PB), i.e., casting, boring, and milling. From the input parameters, which describe the materials and stock and final part geometries, the manufacturing analysis solver calculates total process energy use and equivalent $\mathrm{CO}_{2}$ emissions ( $\mathrm{kg} \mathrm{CO}_{2}$ eq.). The process carbon footprint ( $\mathrm{kg} \mathrm{CO}_{2}$ eq.) values for two variants are then displayed numerically and graphically for interpretation.

With the design and manufacturing/supply chain analysis functionalities thus available in the collaboratory, learning modules can be constructed for use in the classroom at multiple complexity and comprehensiveness levels to educate a wide spectrum of learners about the concepts and practice of sustainable product development. In the sample learning module presented herein, we use the design of a bicycle pedal as a sample project. The sample learning module includes four parts as shown in Table 1; these modules are discussed in greater detail below.

Table 1. Key parts of the sample learning module

Module Part I. Introduction to the Activity

Module Part II. Software Demonstration

Module Part III. Bicycle Pedal Analysis Project

Module Part IV. Discussion

In Part I and Part II, the overall process, anticipated activity, and software (collaboratory) capabilities are explained to the participating students. Students at all levels are familiar with bicycles, but may not be aware of the variety of pedal types available. Thus, the module would start with an introduction and discussion of bicycle pedal types, which include platform, clipless, and pedals with toe clips. Images could be displayed using a projector, or actual pedals could be passed around the classroom to show the many types and styles.

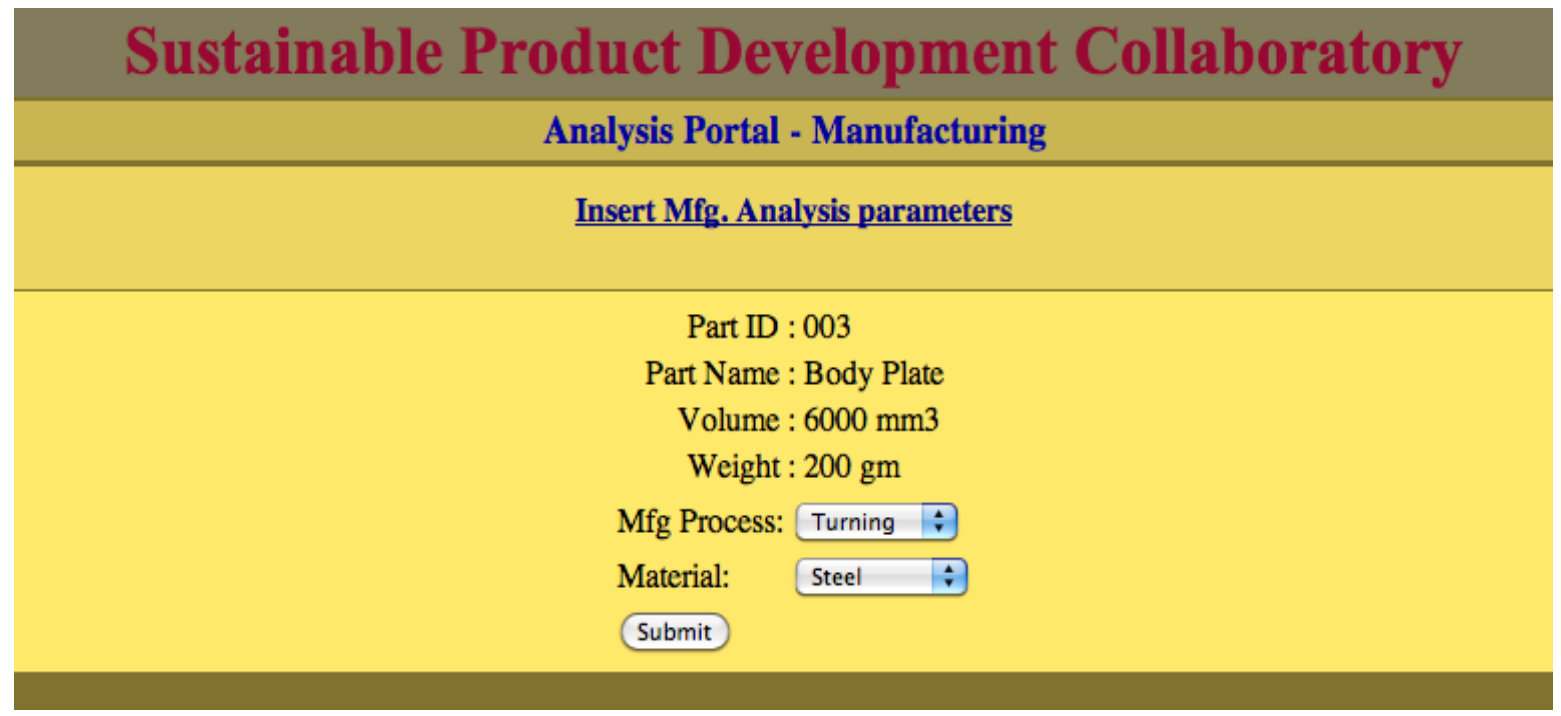

Figure 5. Interface showing properties collected from the PDDB and user defined input fields. 


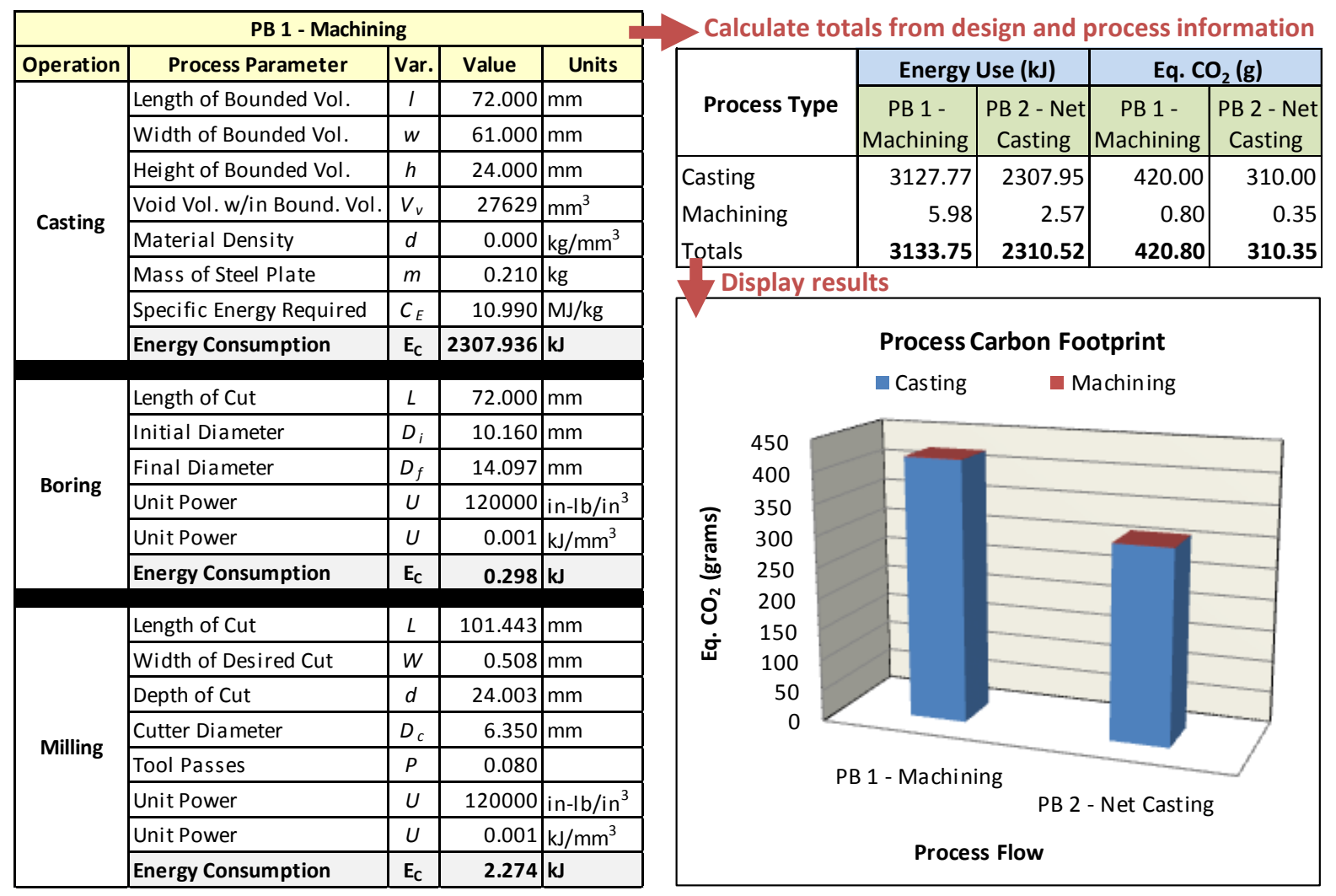

Figure 6. Manufacturing analysis solver operation.

In Part III, students would undertake a pedal design project using the collaboratory, working individually or in pairs, to evaluate the different pedal designs and/or approaches to produce and assemble the pedals. Based on what the students discover, the instructor can lead a discussion in Part IV of the module to further cement the concepts of cost and environmental impact, as well as how they can be influenced by product and process designs. The instructor may conclude the discussion with how this might relate to purchasing decisions students make in their own lives.

This module would be preceded by and concluded with subject matter pre- and post-tests to assess the knowledge gains in students. The tests are designed to assess multiple topics related to design activities completed with the collaboratory e-learning platform. Each pedal design requires different types and amounts of materials, different manufacturing processes to produce, and different supply chains to provide parts and materials for the pedal. By evaluating the set of pedal types within the collaboratory library, students at different levels of learning can thus explore different environmental effects (e.g., carbon footprint and energy consumption) of design changes. At higher levels of learning, students can be asked to change the design parameters (e.g., size) and engineering properties (e.g., material) using Google SketchUp along with the collaboratory.

\section{FOCUS GROUP STUDY}

To validate the concept of employing the collaboratory within a learning module, an interview was conducted with a focus group consisting of middle and high school teachers in Michigan. In the State of Michigan, Next Generation Science Standards (NGSS, http://www.nextgenscience.org/) are being implemented with strong emphasis in ecosystems, sustainability, and human impacts. During the focus group interviews, the teachers supported adoption of this collaboratory concept into the new curriculum. They opined that the subject of human impact on the environment, which is covered in eighth and ninth grades, is the topic where the sustainability design education fits well. In general, the teachers agreed that "understanding how an end product was realized and delivered to consumers" should be emphasized more, especially with respect to human impact on the environment. The scenario based sustainable design education activity aims to tackle these curricular needs.

In order to test the usability of the collaboratory in the classroom, another focus group study was conducted with a modified TaskTechnology Fit questionnaire [13]. Ten graduate students responded to this survey, which consisted of 20 questions. The respondents indicated the ability of the system to conduct the assigned design task using a 7 point Likert scale (1: strongly agree - 7: strongly disagree). The assigned design task was to evaluate the pedal types and explore the effect on environmental performance (i.e., energy consumption) of design changes. Each pedal design requires different types and amounts of materials, different manufacturing processes to produce, and different supply chains to supply parts and materials.

Most questions received an average response of approximately 2 points (Figure 7), which indicates that respondents strongly agreed with the statements. In addition, the standard deviations for most of the responses are 1 to 1.5 , pointing to the fact that most of the respondents evaluated the system with the positive portion of the scale (i.e., 1-4). 


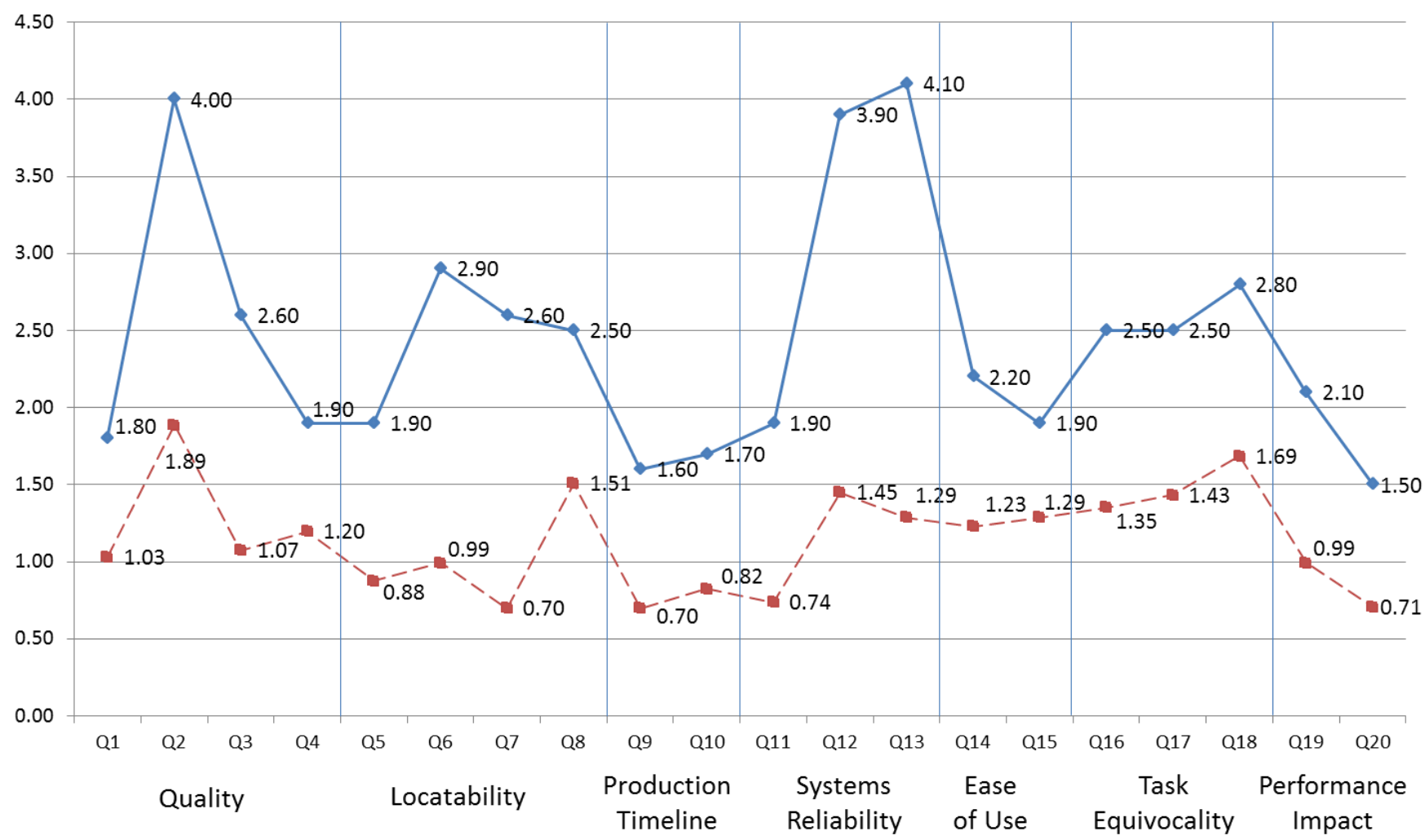

\section{Average $\quad--\div--$ Standard Deviation}

Figure 7. Collaboratory usability test results.

However, two questions about Systems Reliability, i.e., "The Collaboratory system is subject to unexpected or inconvenient down times, which makes it harder to do this work" (Q12) and "The Collaboratory system is subject to frequent problems and crashes" (Q13) had averages of 3.9 and 4.1, respectively. Thus, the system reliability must be improved to be more robust for a better user experience. In addition, the average of the question about Quality, "The Collaboratory system is missing critical data that would be very useful in this job" (Q2) was 4.0 (standard deviation of 1.8). Q2 relates to the ability of the system to maintain the data, which was needed by the users, thus improved ability of the system to maintain data is needed for users to identify changes in the data and to access the previous and current data easily.

This section demonstrated the collaboratory usability assessment, which shows the effectiveness of the collaboratory for the given design task, i.e., evaluating the impact of different pedal designs on environmental performance. The following section describes a proposed method for knowledge assessment.

\section{KNOWLEDGE ASSESSMENT}

The knowledge assessment targets the cyberinfrastructure competency gained through interaction with the Sustainable Product Development Collaboratory as well as content knowledge gained through pre- and post-tests. Pre- and post-testing focuses on the following three learning objectives:
1) Developing an awareness and understanding about the impacts of product architecture, manufacturing process, and supply chain decisions on the economic and environmental sustainability of a product;

2) Articulating the impacts of product architecture, manufacturing process, and supply chain decisions on the economic and environmental sustainability of a product; and

3) Developing product design solutions that address technical requirements, in addition to economic and environmental sustainability goals.

These objectives cover students' knowledge gains through abstract means as well as a more applied project-based approach, and thus, we use Kolb's Learning model [16] as a basis in crafting our assessment questions. In this model, knowledge construction is assumed to progress in various stages, which are not necessarily experienced in order. These stages include

Stage 1: Observation of concrete situations from different perspectives (Concrete Experience - CE)

Stage 2: Observation and reflection of the experiences (Reflective Observation - RO)

Stage 3: Formation of abstract concepts and generalizations based on experiences and reflections (Abstract Conceptualization - AC)

Stage 4: Testing the implications of the concepts and generalizations (Active Experimentation - AE). 
In its essence, the collaboratory is a medium for students to actively experiment with a concrete situation (product design) to test the learned concepts, in addition to providing guidance as critical domain knowledge. Active experimentation also fits well with the constructionist approach, which encourages learning through constructing, or designing or making a product [20].

The knowledge-gain assessment questions that we have developed are open-ended in nature, and tap into awareness of the concepts and the level of articulation. The questions also involve solving problems using the concepts learned; therefore, they cover all stages in Kolb's Learning model. Sample questions that can be used to assess knowledge gain include the following:

In your own words, explain what you understand about the environmental impact of a product.

Explain the contribution of different life cycle stages on the environmental impact of a product.

Which of the following statements best describes your understanding of current product design practice?

Student responses to knowledge assessment pre- and post-tests will be evaluated based on the pre-recorded correct answers to assess the level of knowing on this particular subject - sustainable design, manufacturing, and supply chain management.

By using this sample learning module and the design activities, it is anticipated that students will be able to analyze the relative impacts of components of a particular pedal, as well as the effects of changes to their related geometries, manufacturing processes, and supply chains. The actual implementation and assessment results will be reported in an upcoming article.

\section{CONCLUDING REMARKS}

This article presented a pedagogical framework and a sample learning module developed under an NSF CI-TEAM Demonstration project, entitled "A Sustainable Product Development Collaboratory." This project aims to educate a wide spectrum of learners (K-12, university, industry) in sustainable design and manufacturing by demonstrating the effects of different product designs on supply chain costs and environmental impacts. The presented collaboratory has the potential to create an evolving design repository, promote empirical/experimental investigation to model life cycle costs and environmental performance, and advance methods for joint optimization of design variants and supply chains, while being readily available and reusable by students and practitioners. In addition, the collaboratory stands to benefit educational research by providing a platform for experimental learning module development, implementation, and assessment in the classroom environment at multiple levels and in multiple regions.

A focus group study was conducted to understand middle school and high school teacher's perspectives. While they stated the importance of sustainability education and relevancy of the collaboratory concept to their curricula, they also emphasized that student constructivist learning behavior should be addressed. The teachers indicated that a game type or competition based learning environment is effective. The collaboratory will be further enhanced to support this constructivist pattern of learning.

Collaboratory development is focused on designing a bicycle pedal by considering sustainability principles in design, manufacturing, and supply chain activities. However, evaluating sustainability implications of a product design decision should include the impacts of the overall product life cycle. In other words, products that are superior when manufacturing performance metrics are taken into account may not be the ideal choice when considering other life cycle aspects (e.g., service or end of life). Thus, performance of other life cycle stages will be continuously included in this scalable collaboratory environment.

\section{ACKNOWLEDGMENTS}

This work is funded by the National Science Foundation under grant numbers OCI-1041423 (Oregon State), OCI-1041328 (Penn State), and OCI-1041380 (Wayne State).

\section{REFERENCES}

[1] Allen D, Allenby B, Bridges M, Crittenden J, Davidson C, Hendrickson C, Matthews S, Murphy C, Pijawka D (2008). Benchmarking Sustainable Engineering Education: Final Report. EPA Grant Number: X3-83235101-0.

[2] Ambient Insight. (2011). 2011 learning technology research taxonomy: Research methodology, buyer segmentation, product definitions, and licensing model. Monroe, WA: Author. Retrieved from www.ambientinsight.com/Resources/Documents/AmbientIns ight_Learning_Technology_Taxonomy.pdf

[3] Barbour, M. K. (2009). Today's student and virtual schooling: The reality, the challenges, the promise... Journal of Distance Learning, 13, 1, 5-25.

[4] Barbour, M. K. (2011). The promise and the reality: Exploring virtual schooling in rural jurisdictions. Education in Rural Australia, 21, 1, 1-20.

[5] Barbour, M. K., \& Reeves, T. C. (2009). The reality of virtual schools: A review of the literature. Computers and Education, 52, 2, 402-416.

[6] Carew, A., Mitchell, C. (2008). Teaching sustainability as a contested concept: capitalizing on variation in engineering educators' conceptions of environmental, social and economic sustainability. Journal of Cleaner Production, 16, $1,105-115$

[7] Cavanaugh, C., Barbour, M. K., \& Clark, T. (2009). Research and practice in K-12 online learning: A review of literature. International Review of Research in Open and Distance Learning, 10, 1. http://www.irrodl.org/index.php/irrodl/article/view/607

[8] Cavanaugh, C., Gillan, K. J., Kromrey, J., Hess, M., \& Blomeyer, R. (2004). The effects of distance education on $K-$ 12 student outcomes: A meta-analysis. Naperville, IL: Learning Point Associates. Retrieved July 4, 2005, from http://www.ncrel.org/tech/distance/k12distance.pdf.

[9] Christensen, C. M., Horn, M. B., \& Johnson, C. W. (2008). Disrupting class: How disruptive innovation will change the way the world learns. New York : McGraw-Hill.

[10] Clark, T. (2001). Virtual schools: Trends and issues - A study of virtual schools in the United States. San Francisco, CA: Western Regional Educational Laboratories. Retrieved July 4, 2005 from http://www.wested.org/online_pubs/virtualschools.pdf

[11] Clark, T. (2007). Virtual and distance education in North American schools. In M. G. Moore (Ed.), Handbook of 
Distance Education (2nd ed., pp. 473-490). Mahwah, NJ: Lawrence Erlbaum Associates, Inc.

[12] Dankwort, C. W., Weidlich, R., Guenther, B., and Blaurock, J. E. (2004). Engineers' CAx education - it's not only CAD. Computer-Aided Design, 36, 1439-1450.

[13] Goodhue, D. L. and Thompson, R. L., (1995) TaskTechnology Fit and Individual Performance. MIS Quarterly, $19,2,213-236$

[14] Kafai, Y. (2001). The educational potential of electronic games: From games-to-teach to games-to-learn. Paper presented at the Playing by the Rules: The Cultural Policy Challenges of Video Games, Chicago, IL.

[15] Kafai, Y., Ching, C. C., \& Marshall, S. (1997). Children as designers of educational multimedia software. Computers in Education, 29, 2, 117-126.

[16] Kolb, D. A. (1984). Experiential Learning: experience as the source of learning and development. New Jersey: PrenticeHall (0 132952610$)$

[17] Maloney, J. H., Peppler, K., Kafai, Y., Resnick, M., \& Rusk, N. (2008). Programming by choice: urban youth learning programming with scratch. Proceedings of the 39th SIGCSE Technical Symposium on Computer Science Education, Portland, OR, USA.

[18] Moore, M. G. (1973). Toward a theory of independent learning and teaching. Journal of Higher Education, 44, 12, 661-679.

[19] NSF 2007 MT21 Study, http://www.nsf.gov/news/news_summ.jsp?cntn_id=110845
[20] Papert, S. (1980). Mindstorms: Children, Computers, and Powerful Ideas. New York: Basic Books.

[21] Peppler, K. A., \& Kafai, Y. (2007). From SuperGoo to Scratch: Exploring creative digital media production in informal learning. Learning, Media and Technology, 32, 2, 149-166.

[22] Resnick, M. (2009). Scratch programming for all. Communications of the ACM, 52, 11, 60.

[23] Rice, K. L. (2006). A comprehensive look at distance education in the K-12 context. Journal of Research on Technology in Education, 38, 4, 425-448.

[24] SME Competency Gap Research, http://www.sme.org/downloads/foundation/Competency_Ga p.pdf, Accessed 12/28/06.

[25] Thota, R. and Dwivedi, S. (2006). Implementation of product realization concepts in design and manufacturing course. ASEE paper, 2006-2180.

[26] Vygotsky, L. S. (1962). Thought and Language (E. Hanfmann \& G. Vakar, Trans.). Cambridge, MA: The M.I.T. Press.

[27] Vygotsky, L. S. (1978). Mind in society: The development of higher psychologist processes. Cambridge, MA: Harvard University Press.

[28] Watson, J., Murin, A., Vashaw, L., Gemin, B., \& Rapp, C. (2011). Keeping pace with K-12 online learning: An annual review of policy and practice. Evergreen, CO: Evergreen Education Group. 